\title{
ARTIGOS
}

https://doi.org/10.5007/2175-8042.2018v30n56p11

\section{Entre o corpo vivo e o corpo vivido do sujeito jogador: uma ontogênese estética e estesiológica nos jogos eletrônicos esportivos}

\author{
Bruno Medeiros Roldão de Araújo' \\ Clara Maria Silvestre Monteiro de Freitas ${ }^{2}$
}

\section{RESUMO}

Entendendo que o corpo conhece a si mesmo por meio da expressão do corpo vivo no corpo vivido, com base na Emersiologia, esta pesquisa objetivou conhecer os processos pelos quais as tecnologias maquínicas e informacionais, constituídas na forma de jogos eletrônicos, atuam na cultura corporal de movimento. Realizou-se pesquisa qualitativa descritiva de campo, por meio de entrevistas semi-estruturadas com 50 atores sociais, na faixa etária da juventude, da rede pública de Ensino Médio e Superior da Universidade de Pernambuco - UPE, Recife-PE. As informações foram tratadas por meio da Análise de Conteúdo. Os dados possibilitaram a criação de quadro categórico analítico, que apresentou como principal categoria a "aprendizagem corporal/esportiva por imitação". Conclui-se que, no processo de virtualização corporal, o corpo continua sendo o centro do processo perceptivo, no qual artes imersivas fazem despontar a essência do "iceberg" corporal.

Palavras-chave: Corpo humano. Jogos de vídeo. Empatia

1 Doutor em Educação Física. Professor da Universidade Federal de Campina Grande (UFCG). Sumé/Paraíba, Brasil. E-mail: bruno.rol@gmail.com

2 Doutora em Ciências do Esporte. Professora da Universidade de Pernambuco (UPE). Recife/Pernambuco, Brasil. E-mail: clarasilvestre@gmail.com 
Between the live body and the living body of the player subject: an aesthetical and estesiological ontogenesis in sports video games

\begin{abstract}
Understanding that the body knows itself through the expression of the living body in the lived body based on the Emersiology, this research aimed to know the processes by which mechanical and informational technologies constituted in the form of video games act in the body culture of movement. A descriptive qualitative field research was carried out through semi-structured interviews with 50 social actors in the youth age group of the public high school and college at University of Pernambuco - UPE, Recife, Brazil. The information was handled through the Content Analysis. The data enabled the creation of categorical analytical framework, which presented as its main category the "corporal/sportive learning by imitation". It is concluded that in the process of body virtualization, the body remains the center of the perceptive process, in which immersive arts bring out the essence of the body's "iceberg".
\end{abstract}

Keywords: Human body. Video games. Empathy

Entre el cuerpo vivo y el cuerpo vivido del jugador sujeto: una ontogénesis estética y estesiológica en videojuegos deportivos

\title{
RESUMEN
}

Entendiendo que el cuerpo se conoce a través de la expresión del cuerpo vivo en el cuerpo vivido basado en la Emersiología, esta investigación tuvo por objetivo conocer los procesos por los cuales las tecnologías mecánicas e informacionales constituidas en forma de videojuegos actúan en la Cultura corporal del movimiento. Se realizó una investigación descriptiva cualitativa de campo a través de entrevistas semiestructuradas con 50 actores sociales del grupo de jóvenes de la escuela secundaria pública y universidad de la Universidad de Pernambuco - UPE, Recife. Las informaciones fueran tratadas a través del Análisis de Contenido y los datos han posibilitado la creación de marco analítico categórico. Se concluye que en el proceso de virtualización corporal, el cuerpo sigue siendo el centro del proceso perceptivo, en el cual las artes inmersivas sacan a la luz la esencia del "iceberg" del cuerpo.

Palabras clave: Cuerpo humano. Juegos de video. Empatía 


\section{INTRODUÇÃO ${ }^{3}$}

A sociedade tecnocientífica contemporânea promove processos de virtualização do corpo, que podem ser compreendidos por três óticas principais. A primeira seria a virtualização subjetiva do corpo, em que o corpo é elevado à potência em ambientes virtuais, promovendo novas subjetivações que se atualizam no corpo dito real. Processo este, notadamente observável na prática dos jogos eletrônicos estilo Social Network Games - SNG (KATO; IGARASHI, 2016), que podem ser classificados em: Massively Multiplayer Online Role-Playing Game - MMORPG; Massively Multiplayer Online Game - MMOG; e Multiplayer Online Battle Arena - MOBA, no qual as pessoas interagem online e outra realidade é simulada em ambientes virtuais, geralmente fantasioso e com batalha em campo figurado. De toda forma, o processo de virtualização subjetiva do corpo pode ocorrer em todas as esferas do telespetáculo esportivo, bem como em todos os tipos de jogos eletrônicos, pois está ligado ao processo de virtualização corporal e sua influência na constituição subjetiva dos corpos, um dos pressupostos principais desta tese.

A segunda seria a virtualização objetiva do corpo ou virtualização imediata, na qual o corpo utiliza equipamentos e ferramentas próprias para a imersão nos mundos virtuais. A grande tendência atual e de futuro próximo no mercado dos jogos eletrônicos são os dispositivos de Realidade Virtual - RV ou no inglês Virtual Reality - VR, geralmente na forma de óculos acoplados a headsets (fones de ouvido), proporcionando uma imersão cada vez mais realista no ciberespaço. A RV busca uma simulação perfeita dos ambientes virtuais, nos quais o usuário e/ou jogador, tem visão panorâmica em $360^{\circ}$ do mundo digital, audição com sons gravados e tratados em três dimensões (3D), proporcionando a localização da fonte sonora em diferentes pontos, e na qual o usuário pode interagir com objetos e eventos virtuais (VELEV; ZLATEVA, 2017). A inovação chegou ao grande público do mercado de jogos eletrônicos por meio do dispositivo PlayStation VR (PS VR), lançado na América do Norte e Europa, em outubro de 2016 para o console Playstation 4 da empresa japonesa Sony, ainda sem data oficial de lançamento no Brasil. O dispositivo necessita de uma câmera (que rastreia os sinais luminosos dos demais aparelhos, para localizar o jogador no mundo virtual), a PlayStation camera e pode ser utilizado com os controles/joysticks tradicionais do console da Sony, o Dualshock 4 ou controles especiais nomeados de PlayStation move. Uma das principais concorrentes do mercado de jogos eletrônicos, a empresa norte-americana Microsoft, com o seu console Xbox One (citado anteriormente, e reconhecido destaque dos exergames, por meio do dispositivo de detecção de movimento Kinect 2.0), também prepara o lançamento de seu sistema de RV, o Windows Mixed Reality, que também deverá ser compatível com o próximo console a ser lançado, nomeado de Xbox One $X$.

Cabe destacar também, a tecnologia de Realidade Aumentada (RA), que consiste numa interface tecnológica de interação com o mundo virtual, utilizando uma ou mais 
câmeras que levam a imagem do sujeito jogador ou de algum objeto para dentro do mundo virtual ou incluí personagens e/ou objetos virtuais na imagem do mundo dito real, no qual interagem mutuamente. No caso dos jogos eletrônicos, utiliza os gestos dos jogadores para a interação física/virtual (HENDERSON; FEINER, 2010), tendo como grande destaque o jogo Pokémon Go (jogo baseado na animação Pokémon, que já teve várias adaptações em forma de jogos eletrônicos, sendo está a primeira a utilizar a RA), da produtora japonesa Nintendo em parceria com a Niantic, lançado em julho de 2016 para os sistemas android e iOS, tornando-se o grande divulgador e popularizador da RA para o grande público. Pokémon Go interessa especialmente a Educação Física, pois, segundo Boulos et al. (2017), promove a atividade física (visto que é necessário o deslocamento do jogador para capturar os "monstrinhos" pokémons) e a redução do estresse.

A terceira seria a representação digital do corpo, marcada pela forma como o corpo é representado nos jogos eletrônicos, tanto no designer como no contexto narrativo. Nesta representação, pode-se analisar a evolução tecnológica da indústria dos jogos eletrônicos: no início da década de 1970 e primeira metade dos anos de 1980, o corpo era representado, muitas vezes, apenas por um ponto (um quadrado muitas vezes), formado por poucos bits e pixels; passando pela digitalização dos corpos nas décadas de 1980 (segunda metade) e primeira metade da década de 1990; o avanço e o domínio da utilização poligonal nos jogos eletrônicos no fim da década de 1990 e na década de 2000, onde os jogos eletrônicos passaram do paradigma 2D (jogos em perspectiva de duas dimensões) para o 3D (jogos tridimensionais, com capacidade de simulação e interação bem próximas à realidade); até as atuais representações, com captura de movimento, imagem corporal e fala de atores que compõem as personagens, juntamente a criação gráfica de alta definição, beirando o fotorrealismo.

Estes processos de representação do corpo acompanharam a evolução das possibilidades de interação do sujeito jogador, bem como do gameplay, promovendo uma interação e uma imersão cada vez mais significativas, possibilitando a constituição da cultura corporal de movimento e também a própria constituição do corpo do jogador, tanto subjetivamente, quanto fisicamente, principalmente com o advento dos exergames. Estas três perspectivas de compreensão do corpo são notáveis exemplos do processo de virtualização corporal, promovendo a constituição subjetiva dos corpos e elevando os horizontes de reflexão e atuação dos profissionais em Educação Física. Diante deste cenário, este estudo busca uma compreensão estética e estesiológica do corpo do sujeito jogador de jogos eletrônicos, ancorando-se na teoria emersiológica proposta pelo filósofo francês Bernard Andrieu (2014, 2015, 2016), professor do departamento de Educação Física da Universidade Paris Descartes.

A emersiologia surge como um novo campo da filosofia, principalmente ligado aos estudos do corpo e de suas manifestações estéticas do movimento, como a dança, entre outras. Ela busca compreender a descontinuidade entre os ditos "corpo vivo" e "corpo vivido", partindo do argumento de atraso de 450 milissegundos (ms) existentes entre o trabalho do cérebro e a transmissão nervosa até à consciência, a capacidade de percepção corporal do corpo vivido. Ou seja, o corpo vivido está sempre em atraso em relação ao corpo vivo. 
Corpo vivido representa o corpo carregado de sentidos e significados, o corpo construído socioculturalmente, que carrega uma história, uma significação do movimento consciente e inconsciente. Seria a motricidade, a virtualidade (em potencialidade). O corpo vivo, por sua vez, pode ser compreendido como o corpo atual, que executa sua ação motriz no agora. Seria a mobilidade no tempo presente de sua execução, a atualidade (resultado da potencialidade).

Sobre a emersiologia, Andrieu (2014) afirma ser "[...] uma ciência reflexiva nascida da emersão dos sensíveis provindos de nosso corpo vivo na consciência do corpo vivido [...]. A emersão [...] é o movimento involuntário em nosso corpo de redes, humores e imagens as quais nossa consciência conhece apenas a parte emergida." (ANDRIEU, 2014, p. 07). O autor também demonstra que há uma íntima relação entre a emersiologia e a fenomenologia de Merleau-Ponty (1976). Andrieu (1993), ao estudar a história do corpo no século XX, apresenta três modelos essenciais para a filosofia do corpo: o fenomenológico; o psicanalítico; e o das neurociências. Chegando à conclusão de que a emersiologia está, justamente, na interface dessas três abordagens, das relações do corpo vivido e do corpo vivo e, também, na conjunção das experiências estesiológicas (ANDRIEU; NÓBREGA, 2016).

Compreende-se por estesiologia do corpo uma ciência dos sentidos (MERLEAU-PONTY, 1995), na qual é ampliada a visão positivista sobre a "sensação", na relação causal unidimensional de estímulo-resposta, tornando a sensação e, portanto, a estesiologia, como algo que abrange a maneira pela qual o ser humano conforma o seu esquema corporal e a sua intercorporeidade como dimensão ontológica e existencial (ANDRIEU; NÓBREGA, 2016). Portanto, a emersiologia busca, por meio da estesiologia (expressando sensações, sentimentos e experiências corporais), da fenomenologia e da interface entre os corpos vivo e vivido, superar ideias filosóficas ou psicanalíticas e científicas. Criando uma nova "[...] perspectiva de compreensão da corporeidade que reúna essas dimensões em um processo de descontinuidade entre o corpo vivo e sua experiência vivida." (ANDRIEU; NÓBREGA, 2016, p. 372).

Diante deste cenário, pode-se compreender a emersiologia como a ciência que estuda a maneira pela qual o corpo vivo adapta o corpo vivido para a ação, a mais imediata possível, buscando mascarar a disparidade de tempo entre eles. Essa adaptação não é intencional, é subconsciente e resulta da ecologia ${ }^{4}$ pré-motriz incorporada no habitus, "[...] orientada por esquemas sensoriais elaborados no curso da experiência e que fornece esse caráter intuitivo e espontâneo ao gesto da ação." (ANDRIEU, 2014, p. 7). Ou seja, o corpo vivo realiza gestos e tomam decisões de forma imperceptível, para uma melhor adaptação as modificações ambientais encontradas. O corpo vivo sente, sofre, goza, antes mesmo que se tome conhecimento pelo corpo vivido, que é a consciência, demonstrando ser um modo de subjetivação.

4 Aqui o termo ecologia, refere-se à Ecologia Corporal. Nesta concepção, o corpo é visto como o primeiro meio ambiente do ser humano, a ecologia considera o ser humano pela maneira como o seu corpo interage e modifica o meio onde vive (SÁNCHEZ, 2011). A ecologia corporal se propõe modificar a relação do corpo com a natureza e o meio ambiente, a partir de uma modificação da consciência, de um despertar sensorial e de uma emersão do corpo vivo. (ANDRIEU, 2016). 


\begin{abstract}
A emersiologia busca investigar essa atividade que se passa abaixo do limiar de consciência, em particular por meio dos relatos em primeira pessoa de experiências vividas em situações diversas tais como o orgasmo, a vertigem, a doença, a relação com o outro, a criação artística [...]. A emersiologia ao considerar essa atividade do corpo vivo busca construir uma ontologia do corpo a partir de relatos autobiográficos a respeito de experiências vividas, havendo uma descontinuidade entre o que se passa ou se passou no corpo vivo-, considerando-se a atividade do cérebro abaixo do limiar de consciência- e o próprio relato do vivido. (ANDRIEU; NÓBREGA, 2016, p. 374).
\end{abstract}

Portanto, a emersiologia enquanto método, busca a compreensão do vivo das sensações internas, que não pode ser expresso em sua totalidade por meio de relatos das experiências vividas. Por este motivo, essa perspectiva teórica foi escolhida para uma melhor compreensão da constituição subjetiva do corpo do sujeito jogador, amparando-se na análise de conteúdo dos discursos dos atores sociais entrevistados, na reflexão com os jogos eletrônicos esportivos e de realidade virtual, nas quais a ação e a visão do jogador são em primeira pessoa. Esta perspectiva dos autores sociais em primeira pessoa é adotada e indicada pelo próprio Andrieu, que, ao aplicar seu método de pesquisa, utiliza câmeras GoPro (específicas para gravação de performances de movimento, como as esportivas, e geralmente na perspectiva de visão do atleta) adicionadas ao corpo de modo auto reflexivo.

Figura 1 - Esquema de emersão cognitiva em primeira pessoa do corpo vivo.

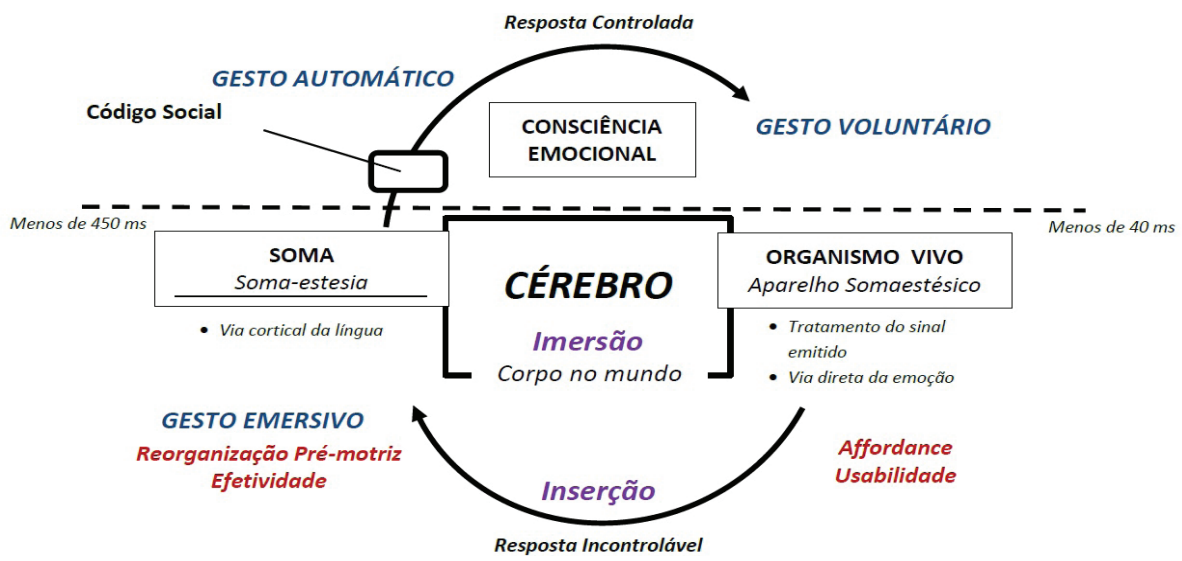

Fonte: Andrieu (2014, p. 7).

A figura 1 ilustra o esquema da emersiologia a partir da emersão cognitiva, em primeira pessoa, do corpo vivo. Comparando à fenomenologia da percepção consciente, há o fato de que não se está em contato direto com as próprias sensações, visto que elas 
são ativadas no corpo sem que se dê conta. Como dito anteriormente há um atraso na consciência corporal, e o que se percebe em primeira pessoa, na narrativa fenomenológica, seria "[...] uma deformação perceptiva do conteúdo que emerge inconscientemente desde o nosso cérebro [...]. Esse filtro da consciência muda a qualidade e intensidade da sensação primeira que surgiu no corpo." (ANDRIEU, 2014, p. 5).

O que a figura demonstra, além do que já foi explanado até aqui, é que as modificações biológicas do corpo vivo passam despercebidas até o momento em que a consciência se aperceba dos signos emersivos, por meio da sensibilidade. Tem-se o corpo vivo, enquanto organismo, conectado ao mundo pelo sistema somaestésico, no qual a capacidade de uso (usabilidade) ou affordance lança uma informação permanente e autorregulada, a qual acontece mesmo com a consciência do corpo vivido adormecida, bem como em estado de vigília e nos gestos automáticos habituais do cotidiano. Este tipo de saber sem conhecimento é ao mesmo tempo vivo no corpo e para estabelecer uma continuidade entre os diferentes níveis do corpo, só mesmo numa compreensão de unidade corpo-espírito (ANDRIEU, 2014).

Por conseguinte, com base na emersiologia, na subjetivação e na virtualização, esta pesquisa ${ }^{5}$ procura responder a seguinte problemática: em que medida os processos tecnocientíficos de virtualização corporal, vinculados aos jogos eletrônicos, vem interferindo na constituição dos corpos?

\section{MÉTODO}

Com o objetivo de conhecer os processos pelos quais as tecnologias maquínicas e informacionais, constituídas na forma de jogos eletrônicos, atuam na cultura corporal de movimento, foi realizada pesquisa qualitativa descritiva de campo, por meio de entrevistas semiestruturadas, aplicação de questionários e observação não-sistemática (FLICK, 2004) com 50 atores sociais (AS). Realizou-se também Grupo Focal com oito (08) AS selecionados aleatoriamente entre estes. Na parte prática, utilizou-se o jogo eletrônico Kinect Sports Rivals produzido pela Rare e Microsoft Studios, um pacote de jogos esportivos (tiro ao alvo, corrida aquática com jet sky, boliche, futebol, tênis e escalada) simulados com auxílio da ferramenta de captação de movimento corporal dos jogadores (Kinect 2.0) e os transfere para a ação em tela, no console Xbox One de 500 GB com Kinect da Microsoft. Com duração aproximada de 10 minutos para cada par de jogadores (quatro pares), acumulando um tempo total aproximado de 40 minutos, também foram utilizados projetor datashow e caixas de som. Após esta prática, realizou-se o debate com base nas questões norteadoras do roteiro pré-estabelecido ${ }^{6}$.

5 Esta pesquisa recebeu apoio do CNPq (Chamada MCTI/CNPQ/Universal, Processo nº. 443529/2014-0) e da CAPES (Programa de Formação Doutoral Docente - Prodoutoral).

6 Este artigo é parte da tese de doutorado "O corpo na dimensão das relações tecnológicas: uma análise dos jogos eletrônicos e do telespetáculo esportivo" do primeiro autor sob orientação da segunda autora. 
Adotou-se a faixa etária da juventude, proposta pela Organização das Nações Unidas - ONU (2004), de 15 a 24 anos de idade, de ambos os gêneros, da rede pública de Ensino Médio e Superior da Universidade de Pernambuco - UPE, na cidade de Recife PE. A quantidade de indivíduos seguiu as recomendações de Bauer e Gaskell (2008), que sugerem para pesquisas qualitativas um limite entre 15 e 25 entrevistas individuais por lócus de investigação, que se justificou pela saturação dos dados obtidos. Adotaram-se como critérios de inclusão que: os atores sociais praticassem ou jogassem jogos eletrônicos, a faixa etária normalmente correspondente ao Ensino Médio (limitada entre 15 a 18 anos de idade) e, no caso dos universitários, respeitou-se os limites da juventude proposto pela ONU (até os 24 anos de idade). Quanto aos critérios de exclusão, foram adotados os aspectos: matrícula em outro nível de ensino; faixa etária inferior ou superior ao delimitado; a não aceitação de voluntariado na pesquisa; e a não anuência e/ou assentimento dos pais e/ou responsáveis, quando era o caso ${ }^{7}$.

A triangulação dos dados foi realizada entre os resultados obtidos nas diferentes formas de coleta. Os dados passíveis de quantificação foram tratados segundo a estatística descritiva, por meio do software SPSS (v.10). Por sua vez, os dados oriundos dos discursos foram analisados com base na Análise de Conteúdo, um recurso da análise categorial, ou seja, delimitação de unidade de codificação, assumida pelo analista que, a partir da totalidade de um texto e em nome de um ideal de objetividade e racionalidade, verifica, com base em critérios de classificação, a frequência ou ausência de itens de sentido (BARDIN, 2011). Foram empregados dois softwares auxiliares: Analysis of Qualitative Data - AQUAD 7 utilizado para buscar a frequência das palavras nos discursos; e o GoDiagram Express for. NET Windows Forms (version 2.6.2), utilizando a ferramenta StateCharter para a construção de diagrama de categorias analíticas. Na construção dos diagramas foram agrupados conceitos relativos à categoria principal (caixa de texto na cor laranja), às categorias derivadas (caixa de texto na cor cinza-escura), subcategorias (caixa de texto na cor cinza-clara) e às variáveis (caixas de texto na cor amarela), objeto dos discursos dos Atores Sociais (AS), seguindo uma lógica de expansão a partir da base (categoria analítica principal), em ritmo ascendente, onde as caixas de textos mais elevadas representam as subcategorias analíticas de maior representatividade nos discursos, ligadas a variáveis e subvariáveis de análise.

\section{RESULTADOS}

Dentre os atores sociais, $66 \%$ eram do gênero masculino e $34 \%$ do feminino, 80\% eram universitários e 20\% estudantes do Ensino Médio, com a idade média de 19,88 anos (desvio-padrão de 2,12). Os dados oriundos da análise de conteúdo dos discursos

7 A pesquisa foi aprovada pelo CEP com seres humanos da Universidade de Pernambuco (parecer número: 944.537), com registro via Plataforma Brasil, CAAE: 40214114.1.0000.5207. Foram seguidas todas as diretrizes éticas da pesquisa com seres humanos, recomendadas pela Comissão Nacional de Ética em Pesquisa (CONEP), Resolução 466/12 do Conselho Nacional de Saúde (BRASIL, 2013). 
dezembro/2018

possibilitaram a criação de diagrama categórico analítico, exposto na figura 2 a seguir, que apresenta como principal categoria sintética relacionada ao entendimento de si por meio dos jogos eletrônicos, a "Aprendizagem corporal/esportiva por imitação nos jogos eletrônicos esportivos".

Figura 2 - Diagrama de Aprendizagem corporal/esportiva por imitação nos jogos eletrônicos esportivos em Escola pública de Ensino Médio e Ensino Superior da Universidade de Pernambuco - UPE.

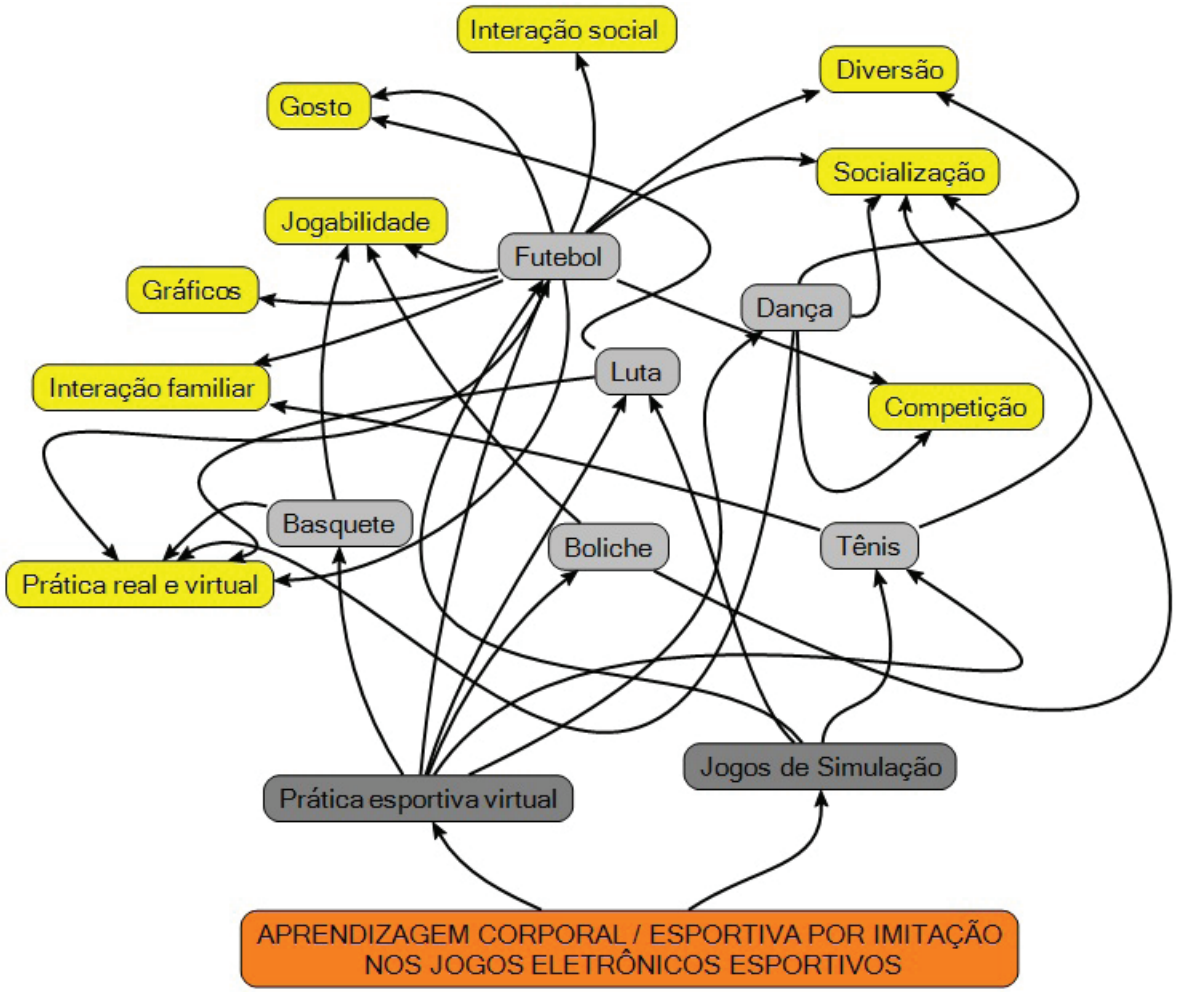

Fonte: os autores com base nos dados da pesquisa.

\section{DISCUSSÃO}

A figura 2 representa a aprendizagem corporal e/ou esportiva por imitação nos jogos eletrônicos esportivos, ou seja, a análise de conteúdo dos discursos do AS, que versaram sobre o aprendizado esportivo e de técnicas corporais, advindas da relação dos AS com a 
prática de jogos eletrônicos esportivos. Este aprendizado esteve ligado à duas categorias derivadas: "Prática esportiva virtual", que representa a prática de jogos eletrônicos esportivos por meio dos exergames, jogos ativos de movimento corporal, atividade e exercícios físicos (VOJCIECHOWSKI et al., 2017; ARAÚJO et al., 2011); e "Jogos de Simulação", que representa os AS que afirmaram jogar as modalidades esportivas, exclusivamente no modo virtual clássico dos jogos eletrônicos, nas simulações que não envolvem exercício físico, numa aprendizagem esportiva, ligada à prática virtual, não necessariamente relacionada às práticas físicas tradicionais destes esportes.

Completando o esquema da figura 2, há nove variáveis que demonstraram se relacionar com uma ou mais modalidades esportivas (subcategorias analíticas). A mais significativa dessas variáveis foi a "Interação social", mesmo que relacionada apenas a uma das modalidades, no caso ao futebol. Cabe uma distinção entre a interação social e a variável "Socialização" que está relacionada também ao futebol, mas, além disso, à dança, ao tênis e ao boliche. Dentro da ótica sociológica, a interação social é a relação social que pode assumir diversas formas, como a econômica, a religiosa, a pedagógica, entre outras, modificando o comportamento dos atores sociais por meio do contato e da comunicação instaurada entre si. Processo este que, para Vygotsky (2001), é fundamental no processo de ensino aprendizagem, estando atrelada à imitação por parte de um ator social que está aprendendo algo em colaboração com outro ator social mais experiente (GASPAR; MONTEIRO, 2005).

Por sua vez, a socialização pode ser compreendida como um processo mais prolongado e complexo, no qual os atores sociais passam do sentido biológico para o sentido sociológico e integram-se em determinado grupo social, adotando os padrões culturais ora vigentes, promovendo a civilidade e, consequentemente, o processo civilizatório (ELIAS, 1969). Estes processos, quando refletidos na ótica da comunicação de massas, na qual os jogos eletrônicos, propagadores de valores, códigos e modelos sociais, ou seja, enquanto artefatos subjetivadores (MENDES, 2006), remetem à chamada Escola de Frankfurt ou Teoria Crítica.

Uma das principais contribuições teóricas da Escola de Frankfurt é o conceito de "indústria cultural" decorrente dos estudos de Horkheimer e Adorno (2002). Conceito este que se integra singularmente aos pressupostos deste artigo, uma vez que os jogos eletrônicos emergem como um produto refinado dessa indústria cultural, e são artefatos de consumo massificados que contribuem para a docilidade social, a felicidade conformista e a satisfação compensatória de seus consumidores. Contudo, por outro lado, promovem também pequenas "rebeliões" contra o sistema ao promover uma ressignificação de si nos mundos virtuais, onde uma realidade paralela pode ser moldada e vivida de maneira mais corajosa e desafiadora que à dita realidade física.

Os jogos eletrônicos produzem saberes decorrentes da atuação do sujeito-jogador que se atualiza, podendo modificar aquela realidade (MENDES, 2006), algo facilmente visto nos jogos do tipo massivo online, conforme os seguintes discursos revelam: 
Eu jogo, quando eu jogo com alguém, eu jogo só online, aquele jogo de cooperação. Você constrói assim tua cidade, pede ajuda para alguém para mandar recurso, ou então visita a cidade da pessoa pra ajudar ela, normalmente é assim. (ATOR SOCIAL no. 20, masculino, 18 anos).

Eu, o único jogo virtual que eu jogo é um que o povo chama de MOBA é League of Legends. Aí lá você tem que criar um avatar, um perfil pra poder jogar. [...] eu sempre analiso o meu posicionamento, é as possibilidades, ahh, o meu inimigo em si, qual o potencial que ele tem sobre mim e qual o potencial que eu tenho sobre ele. [...]. (ATOR SOCIAL no. 27, feminino, 18 anos).

Os discursos abordam os jogos massivos online (Massively Multiplayer Online Role-Playing Game - MMORPG; Massively Multiplayer Online Game - MMOG; e Multiplayer Online Battle Arena - MOBA). Jogos eletrônicos nos quais as pessoas interagem online e outra realidade é simulada em ambientes virtuais, geralmente fantasioso e com batalha em campo figurado ou semelhantes à sociedade atual, numa perspectiva de outra realidade. Os quais, segundo Kato e Igarashi (2016), compõem o estilo Social Network Games - SNG, jogos em rede social que promovem novas subjetividades. Nestes jogos, os sujeitos-jogadores se apropriam dos acontecimentos, dando-lhes representações pessoais, objetivando controlar a realidade psíquica e o seu meio ambiente. Sob a influência da cultura a qual está imerso, num processo de modificação e resistência dos controles institucionalizados pela sociedade (VERZONI; LISBOA, 2015).

A subjetivação é um trabalho de criação de si para si, mediado pela relação com os outros, no qual a empatia é basilar (TISSERON, 2013). Os discursos sobre os jogos eletrônicos estilo SNG demonstram uma relação de empatia recíproca, ligada à necessidade de pertencimento ao grupo, bem como uma empatia recíproca mútua, ou seja, as intersubjetividades decorrentes da expressão fantasiosa e da encenação que marcam a identidade desses jogos eletrônicos.

Continuando a análise das variáveis deste estudo e retornando ao entendimento do processo de ensino aprendizagem nos moldes da teoria vygotskyana, atesta-se que há uma reconfiguração alternativa, uma vez que o ator social desenvolve uma aprendizagem corporal e esportiva, por meio da imitando do seu próprio corpo virtual dos jogos eletrônicos esportivos, numa perspectiva de interação entre o corpo atual e o corpo virtual. Seria uma "interação social" entre o corpo vivo e o corpo vivido? Neste sentido, a emersiologia desponta como uma teoria importante para a explicação deste fenômeno. Cabe focalizar o seguinte discurso,

[...] o Xbox, que você joga com Kinect, que você tem, é mais interação com você mesmo, que você tá ali em pé, corre, faz uma atividade física. Essas coisas assim. (ATOR SOCIAL nº. 07, feminino, 21 anos).

A fala cita os exergames, que promovem uma virtualização objetiva do corpo ou virtualização imediata. Nesse tipo de virtualização o corpo é elevado à potência, mas 
utilizando equipamentos e ferramentas próprias para a imersão nos mundos virtuais. No caso específico, o acessório de detecção de movimento, captura de imagens e sons do corpo dos jogadores para interação física/corporal com os jogos eletrônicos, chamado Kinect do console Microsoft Xbox 360 ou o Kinect 2.0 do console Microsoft Xbox One. Em relação ao uso do Kinect outra fala merece destaque:

[...] esses jogos que você tem que ficar copiando os movimentos, tipo esse da Nike, que quando você não faz do jeito certo ele avisa, e ele fala: "mais pra trás, levanta mais a perna". Ele fica falando. Ou então você pára, tem hora que você cansa, é cansativo, de verdade [...] assim, logo quando você faz o seu cadastro, bota a senha, se você quer ganhar massa, se você quer perder peso. E a partir disso ele faz um treino pra você vendo qual o peso que você está, te analisando tudinho, sua altura, sua idade [...]. (ATOR SOCIAL $n^{\circ}$. 06, feminino, 20 anos).

Este discurso revela o grau de desenvolvimento dos exergames, no qual o jogo eletrônico se aproxima cada vez mais da prática física tradicional dos esportes e do treinamento físico. O jogo em questão se chama "Nike + Kinect Training", lançado em 2012 pela Microsoft e a Nike para o console Xbox 360, jogo que oferece programas individualizados de treinamento físico. Para tal, foram utilizados treinadores pessoais, que tiveram seus conhecimentos técnicos, suas imagens e vozes utilizadas na realidade virtual do jogo, que utiliza da inteligência artificial e de programação algorítmica avançada para direcionar o treinamento e o condicionamento físico dos jogadores, que devem inserir previamente dados corporais e passam por uma avaliação física no próprio jogo eletrônico. Este tipo de virtualização esportiva e corporal demonstra uma singular importância para a Educação Física e o Esporte, por substituir a intervenção profissional na Área, quebrando paradigmas e levando a desdobramentos que ainda não parecem claros para o campo de atuação do Profissional de Educação Física. Observem-se os seguintes discursos:

Olha é bem interessante, porque a gente faz atividade de uma maneira bem dinâmica, tem pessoas que gostam de jogos de videogame, mas também não gostam de fazer atividade física, e isso pode ser uma aproximação à atividade. (ATOR SOCIAL $n^{\circ} .35$, masculino, 22 anos).

[...]. Mas, a partir do momento que se começou a fazer esses jogos, onde se age, aí já se parte pra prática, a execução do movimento, [...]. Então isso leva você a executar corretamente o movimento, então acho muito interessante e sim, uma forma de aprendizado e acredito que poderia haver aulas de Educação Física com a utilização de videogames. [...]. (ATOR SOCIAL nº. 33, masculino, 22 anos).

A elevação do corpo do sujeito-jogador à potência, num processo de virtualização, bem como a atualização deste corpo no movimento intencional do jogador, para interagir e superar os desafios do jogo, são imediatas. Ocorrem quase que simultaneamente. Na verdade, a proposta dos artefatos de interação física com os mundos digitais, a exemplo do Kinect, é justamente a de uma experiência o mais próxima possível da experiência 
real/atual. Cabe destacar que, a noção de virtual e de virtualização adotada neste estudo advém das obras de Pierre Lévy e Gilles Deleuze. Para Lévy (1996), o virtual não se opõe ao real, e sim ao atual, e a virtualização é compreendida como uma potencialização, uma problematização que permite soluções, atualizações. Real e atual seriam apenas duas maneiras distintas de ser no espaço temporal, visto que o virtual tende a se atualizar no momento do tempo presente. Seguindo esta linha de pensamento, a virtualização, processo da dinâmica do virtual, pode ser compreendida como movimento inverso da atualização. Essa concepção de complementação e "antítese/tese", de devir entre o atual e o virtual, foi trabalhada por Deleuze (1996) no que ele nomeou de "plano de imanência".

Para Deleuze, há um circuito em que o atual e o virtual se intercambiam num processo que ele chama de "cristalização", que os tornam praticamente indistinguíveis. Entende-se que seria impossível escapar deste devir, o que remete a outro devir e ocorre entre o corpo vivo e o corpo vivido, pois segundo Andrieu (2016) o corpo conhece a si mesmo por meio da expressão do corpo vivo no corpo vivido (base da teoria emersiológica). Quando o cérebro do sujeito-jogador, ente principal da imersão do corpo no mundo, pensa numa reação para uma determinada ação percebida como necessária pelo organismo vivo e seu aparelho somaestésico nos jogos eletrônicos, seu corpo vivo consciente encaminha o estímulo para que se ativem o movimento dos dedos no joystick ou o movimento dos agrupamentos musculares necessários a determinado exergame. Essa reação ocorre muitas vezes de maneira espontânea, na forma de gesto automático, derivado do gesto emersivo (uma reorganização pré-motriz), que a partir da consciência emocional pode ocorrer de forma controlada, na forma de gesto voluntário com atraso de resposta dos estímulos cerebrais de menos de $40 \mathrm{~ms}$ (ANDRIEU, 2014), vide figura 1 (p. 4). Por exemplo, no grupo focal se observou a habilidade do saltar, movimento básico e aprendido desde a infância de maneira sociocultural, o qual apresenta uma maneira individual e própria de execução, praticamente como um gesto automático. Contudo, os atores sociais o realizavam de forma meticulosa, a fim de garantir uma perfeita leitura do corpo pelo dispositivo de virtualização Kinect, objetivando a melhor pontuação ou superação dos desafios impostos pelo jogo eletrônico. Neste sentido, compreende-se um devir, uma "cristalização" que torna praticamente indistinguível a distinção entre o corpo atual e o corpo virtual. Aqui as intersubjetividades ocorrem simultaneamente ao aprendizado corporal e esportivo. $\mathrm{O}$ seguinte discurso exemplifica em parte a constatação aqui tratada:

Assim, primeiro quando acredito, quando você utiliza algum jogo você adquire conhecimento a respeito daquela modalidade, né? [...]. Quando você usa esse aparelho, você pratica, você exercita, você executa o gesto. Então, acredito que seja muito melhor nesse sentido de aprendizagem. Em algumas situações, de acordo com o adversário. [...]. (ATOR SOCIAL nº. 33, masculino, 22 anos).

Diante deste discurso e do cenário de virtualização, da aprendizagem esportiva e corporal por imitação e da conscientização de si, do corpo vivo com base na emersiologia, 
pode-se destacar a variável "Prática real e virtual" (figura 2, p. 7), relacionada com as subcategorias "Futebol", "Dança", a "Luta" e o "Basquete", que representam as mesmas modalidades que os AS jogam no mundo dito "real" e nos mundos digitais dos jogos eletrônicos esportivos. A subcategoria "Futebol" se destaca como a mais relevante, refletindo a importância do futebol para a constituição da identidade nacional brasileira, reproduzida nas práticas virtuais dos jogos eletrônicos, conforme apontado por Araújo et al. (2011).

As demais variáveis da figura 2, a diversão, o gosto, a jogabilidade, os gráficos, a interação familiar e a competição, refletem os principais motivos e categorias que chamam a atenção na prática dos jogos eletrônicos esportivos. Dentre estas, os gráficos dizem respeito principalmente ao nível de desenvolvimento da representação digital do corpo, nas quais o realismo gráfico atingido e as possibilidades de interação corporal desenvolvidas no gameplay tornam os jogos eletrônicos esportivos atraentes e cada vez mais próximos da realidade esportiva dos jovens, participando assim da conformação de sua cultura corporal de movimento (ARAÚJO et al., 2011).

Outra variável que merece destaque é a "interação familiar", uma vez que os discursos revelaram uma importante participação de irmãos e pais nos jogos eletrônicos, promovendo um processo de interação familiar não-coercitiva (SALVADOR; WEBER, 2005), na qual os atores sociais se entendem por iguais, fazendo os mais jovens desenvolverem uma consciência autônoma e livre na relação com os pais e/ou irmãos mais velhos, coadunando os achados de Moita (2006).

Os discursos do AS remeteram também à realidade virtual, que promove uma importante reflexão sobre a relação do corpo vivo no ambiente virtual dos jogos eletrônicos por ser a nova tendência do mercado dos jogos eletrônicos. Os dispositivos de Realidade Virtual - RV despontam para uma ressignificação da maneira de interação corporal virtual, ao proporcionar ao usuário e/ou jogador uma visão panorâmica em primeira pessoa do mundo digital. Essa perspectiva de visão em primeira pessoa é utilizada principalmente nos jogos do estilo First Person Shooter - FPS (jogos de tiro em primeira pessoa), a exemplo de Counter Strike: Global Offensive - CS: GO, que interessa especialmente à Educação Física, por ser um dos mais reconhecidos e-Sports (SEO, 2013; RAI; YAN, 2009), os esportes eletrônicos, institucionalizados e profissionalizados de maneira similar aos esportes tradicionais (TAYLOR, 2012). Para além dos jogos de FPS, a visão em primeira pessoa também é utilizada em jogos de aventura e ação. E com a chegada dos jogos de última geração que utilizam a realidade virtual, este tipo de perspectiva desponta como o "padrão ouro" para os jogos eletrônicos daqui em diante. Esse tipo de visualização é muito importante para a reflexão dos sentidos na teoria emersiológica proposta por Andrieu (2014, 2015, 2016), que busca investigar as atividades subliminares da consciência, objetivando construir uma ontologia do corpo. Este processo é marcado pela ecologia corporal, num despertar sensorial e de uma emersão do corpo vivo, um tipo de microecologia de transformação da consciência das práticas corporais dos indivíduos, que fazem emergir o "iceberg" corporal, àquela parte da imagem corporal que está inconsciente. 
Os relatos dos atores sociais sobre a experiência do seu corpo vivo nos jogos eletrônicos esportivos demonstraram que estes artefatos tecnológicos e lúdicos facilitam a descoberta da essência corporal, trazida à tona pela atualização imediata do corpo virtualizado, que, segundo Andrieu (2016), seria o corpo viv@ (tradução livre do francês viv@nt), categoria por ele criada com base nos equipamentos e aplicativos de mensuração e monitoração de dados corporais com fins de saúde. Seria um mediador tecnológico que informa a atividade do corpo vivo, mas sem reproduzir na consciência do corpo vivido um modo de ação direta, algo que na proposta deste artigo pode ser ampliado para a consciência do corpo vivido, uma vez que os jogos eletrônicos esportivos e de realidade virtual apontam para uma estesiologia diferenciada, ao expressarem as sensações, os sentimentos e as experiências corporais dos sujeitos jogadores como dimensões ontológicas e existenciais. Nesta perspectiva o corpo do sujeito-jogador conhece a si mesmo, sente a vida ao presente.

\section{CONCLUSÃO}

Os discursos refletiram um processo de criação do movimento humano por meio da reprodução de vivências virtuais, promovendo novos processos de subjetivação e consequentemente de constituição corporal. Diante do anacronismo de transmissão nervosa de 40 a 450 ms até a consciência no corpo vivido, tem-se o reconhecimento do corpo vivo sempre em atraso na consciência do corpo vivido. Neste sentido o corpo vivido seria o virtual e o corpo vivo a atualização deste na expressão de sua cultura corporal de movimento.

Entre o corpo vivo e o corpo vivido do sujeito jogador há uma interface na qual habita o íntimo do sujeito, uma realidade pré-motriz, uma inconsciência consciente dos gestos automáticos. Uma subjetividade que constitui a maneira de ser no mundo, a motricidade e compreensão de si, por meio do corpo que se é. E justamente por ser este corpo no e ao mundo que se alerta: o ser humano é aquilo que se vive. $\mathrm{O}$ corpo pode experimentar outras dimensões neste mesmo espaço dimensional, um dito real e outro virtual, no qual a fluidez identitária apenas serve para uma constituição e compreensão do "ser" no mundo. O corpo não é descartável, pelo contrário, é reconhecido como ente máximo e definitivo da existência.

\section{REFERÊNCIAS}

ANDRIEU, Bernard. A emersão do corpo vivo através da consciência: uma ecologização do corpo. Holos, Natal, ano 30, v. 5, 2014. DOI: 10.15628/holos.2014.2582. Disponível em: <http://www2.ifrn.edu.br/ojs/index.php/HOLOS/article/view/2582/ pdf_120>. Acesso em: 13 dez. 2016.

. Le corps dispersé : une histoire du corps au xx e siècle. Paris : L'Harmattan, 1993. . Sentir son cerveau. Une méthode émersive. Tome 1 de L'Emersiologie. Paris: L'harmattan, 2015. 
Sentir son corps vivant. Émersiologie 1. Paris: Vrin, 2016.

ANDRIEU, Bernard; NÓBREGA, Terezinha Petrucia da. A emersiologia do corpo vivo na dança contemporânea. Holos, Natal, ano 32, v. 3, 2016. DOI: 10.15628/ holos.2016.4187. Disponível em: < http://www2.ifrn.edu.br/ojs/index.php/ HOLOS/article/view/4079/1505>. Acesso em: 13 dez. 2016.

ARAÚJO, Bruno Medeiros Roldão de et al. Virtualização esportiva e os novos paradigmas para o movimento humano. Motriz: Revista de Educação Física (Online), Rio Claro, v. 17, n. 4, p. 600-609, out./dez. 2011. Disponível em: < http://www.scielo.br/pdf/ motriz/v17n4/a04v17n4.pdf>. Acesso em: 13 jan. 2017.

BARDIN, Laurence. Análise de conteúdo. Trad. L. de A. Rego e A. Pinheiro. Lisboa: Edições 70, 2011.

BAUER, Martin; GASKELL, George. (Ed.). Pesquisa Qualitativa com Texto, Imagem e Som. Trad. Pedrinho A. Guareschi. 7. ed. Rio de janeiro: Vozes, 2008.

BOULOS, Maged N. Kamel et al. From urban planning and emergency training to Pokémon Go: applications of virtual reality GIS (VRGIS) and augmented reality GIS (ARGIS) in personal, public and environmental health. International Journal of Health Geographics, London, v. 16, n. 7, p. 1-11, 2017.

BRASIL. Conselho Nacional de Saúde. Resolução n 466/12 do Conselho Nacional de Saúde de 12 de dez. 2012. Diário Oficial da União, Brasília, DF, nº 12, seção 1, p.59, 13 jun. 2013. Disponível em: <http://bvsms.saude.gov.br/bvs/saudelegis/cns/2013/ res0466_12_12_2012.html >. Acesso em: 12 fev. 2017.

DELEUZE, Gilles. O atual e o virtual. In: ALLIEZ, Éric. Deleuze Filosofia Virtual. Trad. Heloísa B. S. Rocha. São Paulo: Editora 34, 1996. p. 47-57.

ELIAS, Norbert. Über den Prozeß der Zivilisation. Soziogenetische und psychogenetische Untersuchungen. 2 vol. 2. ed. Bern: Francke Verlag, 1969.

FLICK, Uwe. Uma Introdução à Pesquisa Qualitativa. 2. ed. Porto Alegre: Artmed, 2004. GASPAR, Alberto; MONTEIRO, Isabel Cristina de Castro. Atividades experimentais de demonstrações em sala de aula: uma análise segundo o referencial da teoria de Vygotsky. Investigações em Ensino de Ciências, Porto Alegre, v. 10, n. 2, p. 227-254, 2005. Disponível em: < https://www.if.ufrgs.br/cref/ojs/index.php/ienci/article/ view/518/315>. Acesso em: 01 abr. 2017.

HENDERSON, Steven; FEINER, Steven. Opportunistic tangible user interfaces for augmented reality. IEEE Transactions on Visualization and Computer Graphics, College Park, v. 16, n. 1, p. 4-16, jan./feb.2010.

HORKHEIMER, Max; ADORNO, Theodor. A indústria cultural: o iluminismo como mistificação de massas. In: LIMA, Luiz Costa. Teoria da cultura de massa. São Paulo: Paz e Terra, 2002. p. 169-214.

KATO, Jin; IGARASHI, Tasuku. The effects of narcissism and self-esteem on immersion in social network games and massively multiplayer online role-playing games. The 
Japanese Journal of Psychology, Tokyo, v. 87, n. 1, p. 1-11, jan. 2016. Disponível em: < https://www.researchgate.net/publication/290473250_The_effects_of_ narcissism_and_self-esteem_on_immersion_in_social_network_games_and_ massively_multiplayer_online_role-playing_games >. Acesso em: 17 fev. 2017. LÉVY, Pierre. O que é o virtual? Trad. Paulo Neves. São Paulo: Editora 34, 1996.

MENDES, Cláudio Lúcio. Jogos eletrônicos: diversão, poder e subjetivação. Campinas: Papirus, 2006.

MERLEAU-PONTY, Maurice. Phénoménologie de la perception. Paris: Gallimard, 1976. . La Nature : notes cours au Collège de France. Établi par Dominique Séglard. Paris: Seuil, 1995.

MOITA, Filomena Maria Gonçalves da Silva Cordeiro. Games: contexto cultural e curricular juvenil. 2006. 181 f. Tese (Doutorado em Educação) - Programa de Pós-graduação em Educação, UFPB, João Pessoa, 2006.

ONU. Informe sobre la juventude mundial 2005. Asamblea General Consejo Económico y Social. A/60/61-E/2005/7. 06 dez. 2004. Disponível em: < http://www.cinu.mx/ minisitio/UNjuventud/docs/A_60_61.pdf>. Acesso em: 21 nov. 2016.

RAI, Laxmisha; YAN, Gao. Future perspectives on next generation e-sports infrastructure and exploring their benefit. International Journal of Sports Science and Engineering, Birmingham, v. 3, n. 1. p. 27-33, 2009. Disponível em: < http://www. worldacademicunion.com/journal/SSCI/sscivol03no01 paper05.pdf $>$. Acesso em: 19 mar. 2017.

SALVADOR, Ana Paula Viezzer; WEBER, Lidia Natalia Dobrianskyyj. Práticas educativas parentais: um estudo comparativo da interação familiar de dois adolescentes distintos. Interação em Psicologia, Curitiba, v. 9, n. 2, p. 341-353, jul./dez. 2005. Disponível em: < http://revistas.ufpr.br/psicologia/article/viewFile/4782/3669>. Acesso em: 03 abr. 2017.

SÁNCHEZ, Celso. Ecologia do corpo. Rio de Janeiro: Wak Editora, 2011.

SEO, Yuri. Electronic sports: a new marketing landscape of the experience economy. Journal of Marketing Management, Durham, n. 29, n. 13-14, p. 1542-1560, 2013. http://dx.doi.org/10.1080/0267257X.2013.822906

SÉRGIO, Manuel. Para uma Epistemologia da Motricidade Humana. 2. ed. Lisboa: Compendium, 1994.

TAYLOR, Tina Lynn. Raisin the stakes: e-Sports and the professionalization of computer gaming. Cambridge: The MIT Press, 2012.

TISSERON, Serge. Introduction. In: TISSERON, Serge et al. Subjetivatios et empathie dans les mondes numériques. Paris: Dunod, 2013. p. 1-29.

VELEV, Dimiter; ZLATEVA, Plamena Ventseslavova. Virtual Reality Challenges in Education and Training. International Journal of Learning and Teaching, Ottawa, v. 3, n. 1, 
p. 33-37, mar. 2017. Disponível em: < https://www.researchgate.net/profile/ Plamena_Zlateva/publication/312213416_Virtual_Reality_Challenges_in_ Education_and_Training/links/5876833408aebf17d3b9a207/Virtual-RealityChallenges-in-Education-and-Training.pdf > . Acesso em: 23 mar. 2017.

VERZONI, André; LISBOA, Carolina. Formas de subjetivação contemporâneas e as especificidades da geração y. Revista Subjetividades, Fortaleza, v. 15, n. 3, p. 457-466, dez. 2015. Disponível em: < http://repositorio.pucrs.br/dspace/ bitstream/10923/9043/2/Formas_de_Subjetivacao_Contemporaneas_e_as_ Especificidades_da_Geracao_Y.pdf >. Acesso em: 15 mar. 2017.

VOJCIECHOWSKI, Audrin Said et al. Effects of exergame training on the health promotion of young adults. Fisioterapia em Movimento, Curitiba, v. 30, n. 1, p. 59-67, jan./ mar. 2017. Disponível em: < http://www.scielo.br/pdf/fm/v30n1/1980-5918fm-30-01-00059.pdf > . Acesso em: 17 jan. 2017.

VYGOTSKY, Lev Semionovitch. A construção do pensamento e da linguagem. São Paulo: Martins Fontes, 2001.

Recebido em: Julho/2017 Aprovado em: Outubro/2017 